\title{
Self-retaining retractor for lacrimal sac operations
}

\author{
MALCOLM LYALL \\ Aberdeen
}

This instrument has been modified from a self-retaining retractor, supposed to be of German origin, designed for use in children's mastoid surgery. It has not been possible to trace its manufacture.

It has a cross-action, and when the teeth come apart they are held by a ratchet which can be released. If the ratchet is released inadvertently the teeth come together, not endangering the globe. The bend on the skin side of the instrument fits the cheek. The teeth are similar to those of the Four-Claw hand-held retractor (Stallard, I958), but shorter, and they retract both orbicularis and skin without tearing. The even firm pressure on the tissues helps to prevent haemorrhage. A good exposure is obtained.

(I)

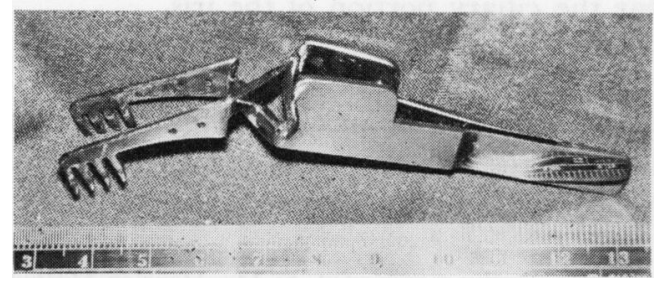

FIG. I The retractor (scale in centimetres)

FIG. 2 The instrument in use
(2)

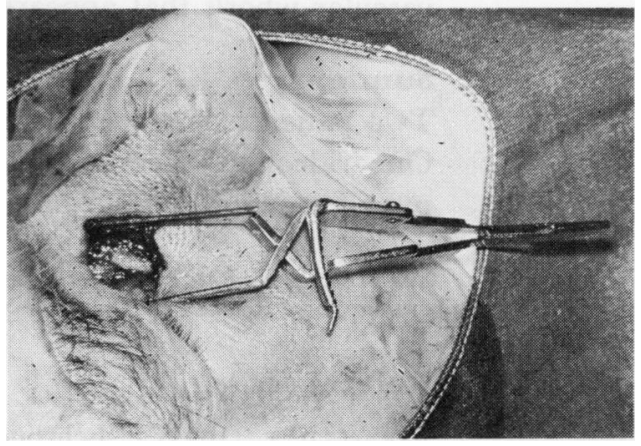

\section{Reference}

STAllard, H. в. ( I 958) “Eye Surgery”, 3rd ed., p. 3 I 2. Wright, Bristol

Received for publication November 4 , $197 \mathrm{I}$

Address for reprints: 54 North Deeside Road, Bielside, Aberdeen, AB t 9l)B

The instrument is available from Dixey Instruments Ltd., London 